Pacific Journal of Mathematics

ARPENE POLYNOMAL APRROXIMATIO 


\section{SHARPENED POLYNOMIAL APPROXIMATION}

\section{Alan G. Law AND ANn L. McKerracher}

In 1951, W. Wolibner showed that a real continuous function on a closed interval can be uniformly approximated by a polynomial which interpolates at prescribed points and which has a uniform norm agreeing with the function's. This fit can be sharpened to include matching of some relative extrema as well. The paper characterizes functions that permit Simultaneous Approximation and Interpolation which is Norm-Preserving and Extrema-Matching over the entire interval except, perhaps, for a subset of arbitrarily-small diameter.

1. Introduction. The classical Weierstrass Theorem of (uniform) polynomial approximation to real, continuous functions has been generalized in many ways [2,3]; one type of extension concerns approximations in various normed linear spaces [3]. However, if the element to be approximated remains in the space of continuous functions on a closed and finite interval, and if the uniform approximation is by polynomial, then the generalizations involve "closeness" of approximation. As an example of this second type, the Walsh result of 1935 [2] shows existence of a uniformly-good polynomial approximation to a function that also interpolates the function at prescribed points. Deutsch and Morris [3] have pointed out that W. Wolibner [4] extended this last result in 1951; he, in essence, proved existence of a polynomial which (uniformly) approximates a continuous function, and which interpolates the function, and whose (uniform) norm is equal to that of the function on the prescribed interval. Theorem 1 shows that such a fit can easily be sharpened to include matching of relative extrema too; that is, finitely-many relative extrema of the function are relative extrema of the approximating polynomial (where a minimum corresponds to a minimum and a maximum to a maximum, of course).

If $f$ has an infinite number of relative extrema, no polynomial can match at all of them-otherwise, the derivative of the polynomial would have an infinite number of zeros. However, some continuous functions have approximating polynomials that match all extreme points except those over a closed set of arbitrarily-small diameter; Theorem 2 shows that a function has such approximating polynomials when, and only when, the points where the function achieves its extrema constitute a (countable) convergent sequence.

Throughout the discussion, the space considered is the set $C[a, b]$ of continuous, real-valued functions endowed with the max norm, 
\|\| , on the closed and finite interval $[a, b]$.

2. Polynomial approximations which match extrema. Wolibner's theorem actually shows that a finite number of points in the plane, for which the ordinates of any two adjacent points are distinct, can be interpolated by a polynomial that preserves monotonicity of the piecewise-linear function, $\phi$, connecting the points. It is clear in the proof of this theorem that the polynomial constructed not only is monotonically increasing or decreasing where $\phi$ is, but is a uniform approximation to $\phi$ as well. Now, any member of $C[a, b]$ can be approximated arbitrarily closely by the piecewise linear function which connects certain points on the graph (a sufficient number with equally-spaced abscissae, for instance). If to such a set of points there are adjoined, if necessary, (i) a point $\left(x_{0}, f\left(x_{0}\right)\right)$ where $\left|f\left(x_{0}\right)\right|=\|f\|$, and (ii) intermediate points so that any two adjacent points in the final set will have distinct ordinates, then Wolibner's development for the corresponding polygonal function gives:

THEOREM 1. Suppose $f$ is a member of $C[a, b]$ and that $t_{i}(1 \leqq$ $i \leqq m)$ are $m$ given values in $[a, b]$. Let $s_{j}(1 \leqq j \leqq k)$ be $k$ points at which $f$ has relative extrema. Then, for any positive $\varepsilon$, there exists a polynomial $p$ such that:

(i ) $\|f-p\|<\varepsilon$,

(ii) $p\left(t_{i}\right)=f\left(t_{i}\right)$ for $1 \leqq i \leqq m$,

(iii) $\|p\|=\|f\|$, and

(iv) $p\left(s_{j}\right)=f\left(s_{j}\right)$ and $p$ has a relative extremum at each $s_{j}$ for $1 \leqq j \leqq k$ (a maximum of $p$ corresponds to a maximum of $f$, and $a$ minimum to a minimum).

Thus, any $f$ in $C[a, b]$ has a polynomial that simultaneously approximates, interpolates, preserves norm and, further, matches extrema at a finite number of points.

Definition. Suppose $f$ is a member of $C[a, b]$, and let $X$ be a given subset of $[a, b] . \quad f$ is said to have property $S$ on $X$ if for any $\varepsilon>0$ and for any prescribed finite subset, $T$, of $[a, b]$ there exists a polynomial $p$ such that:

(i ) $\|f-p\|<\varepsilon$,

(ii) $p(t)=f(t)$ for $t \in T$,

(iii) $\|p\|=\|f\|$, and

(iv) at each point of $X$ where $f$ has a relative extremum, $p$ interpolates $f$ and $p$ has a relative extremum (of the same type) there.

Wolibner's result is that any $f$ has property $S$ on the null set; 
Theorem 1 can easily be used to show that $f$ has property $S$ on $[a, b]$ if, and only if, the set of points in $[a, b]$ at which $f$ has relative extrema is finite. The next theorem characterizes those functions in $C[a, b]$ which have property $S$ on sets $X=[a, b]-V$, where $V$ is a closed set with arbitrarily-small diameter (that is, $d(V)=\sup _{x, y \in V}|x-y|$ is arbitrarily small).

THEOREM 2. For any member, $f$, of $C[a, b]$, the following two assertions are equivalent:

(a) corresponding to any given $\varepsilon>0$, there exists a closed subset $V$, with $d(V)<\varepsilon$, for which $f$ has property $S$ on $[a, b]-V$;

(b) the points of $[a, b]$ where $f$ has relative extrema constitute $a$ (countable) convergent sequence.

Proof. Suppose, first, that the relative extrema of $f$ occur only at $\left\{x_{1}, x_{2}, x_{3}, \cdots\right\}$ and let $x_{0}$, in $[a, b]$, denote the limit of this sequence. For $\varepsilon>0$ the set $V=\left[x_{0}-\varepsilon / 3, x_{0}+\varepsilon / 3\right] \cap[a, b]$ has diameter less than $\varepsilon$ and, by Theorem $1, f$ has property $S$ on $[a, b]-V$.

For the converse, let $E$ denote the set of points in $[a, b]$ at which $f$ has relative extrema. If $E$ is finite, there is nothing to prove; so, suppose that $E$ is infinite. Let $\left\{V_{n}\right\}, n \geqq 1$, be a sequence of closed subsets of $[a, b]$ such that $f$ has property $S$ on $[a, b]-V_{n}$, and such that $d\left(V_{n}\right)<1 / n$ for $n \geqq 1$. Since $E$ is infinite, $\left\{V_{n}\right\}$ has the finite intersection property; thus, $V=\bigcap_{n=1}^{\infty} V_{n}$ is nonempty. But $V \subset V_{n}$ implies that $d(V)=0$ - consequently, $V=\left\{x_{0}\right\}$ for some $x_{0}$ in $[a, b]$. The relation

$$
\begin{aligned}
E & =\{E \cap V\} \cup\left\{E \cap\left([a, b]-\bigcap_{n=1}^{\infty} V_{n}\right)\right\} \\
& =\{E \cap V\} \cup \bigcup_{n=1}^{\infty}\left\{E \cap\left([a, b]-V_{n}\right)\right\}
\end{aligned}
$$

shows that $E$ is a countable union of finite sets and, hence, is countable. Finally, since each $V_{n}$ contains both $x_{0}$ and infinitely-many elements of $E$, and because $d\left(V_{n}\right) \rightarrow 0, x_{0}$ must be the limit of the sequence $E$.

It is, perhaps, not surprising that Theorem 2 no longer holds if diameter is replaced by (Lebesgue) measure $\mu$. Of course, (b) would still imply (a) since $\mu(V)=d(V)$; however, the following example shows that the converse would fail. For each $n=1,2,3, \cdots$, let $\left(a_{n}, b_{n}\right)$ be an open, middle-third interval removed from $[0,1]$ in the construction of the Cantor ternary set $K$. Let $g(x)$ be defined as follows: $g(x)=0$ for $x \in K, g(x)=x-a_{n}$ i $_{-} a_{n}<x<\left(a_{n}+b_{n}\right) / 2$ and $g(x)=b_{n}-x$ if $b_{n}>x \geqq\left(a_{n}+b_{n}\right) / 2$, for $n \geqq 1$. It is easy to check that $g$ is in $C[0,1]$, that it attains its relative minima on $K$ and that it has a relative maximum at $\left(a_{n}+b_{n}\right) / 2$ for each $n \geqq 1$. Thus, the 
corresponding set at which $g$ has relative extrema is uncountable. On the other hand, for any $N \geqq 1, g$ has only a finite number of extrema on $\bigcup_{n=1}^{N}\left(a_{n}, b_{n}\right)$; hence, with $V_{N}=[0,1]-\bigcup_{n=1}^{N}\left(a_{n}, b_{n}\right), g$ has property $S$ on $X=[0,1]-V_{N}$ and $\mu\left(V_{N}\right)$ can be made arbitrarily small.

\section{REFERENCES}

1. K. A. Bush, Pathological functions, crinkly and wild, J. Math. Anal. Appl., 35 (1971), 559-562.

2. P. J. Davis, Interpolation and Approximation, Blaisdell, New York, 1963.

3. F. Deutsch and P. D. Morris, On simultaneous approximation and interpolation which preserves norm, J. Approximation Theory, 2 (1969), 355-373.

4. W. Wolibner, Sur un polynôme d'interpolation, Colloq. Math., 2 (1951), 136-137.

Received February 1, 1973. Work by the first author was supported in part by National Research Council of Canada Grant A-7186.

University of SASKatchewan, REgINA 


\section{PACIFIC JOURNAL OF MATHEMATICS}

\section{EDITORS}

RICHARD ARENS (Managing Editor)

University of California

Los Angeles, California 90024
J. DUGUNDJI*

Department of Mathematics

University of Southern California

Los Angeles, California 90007

D. Gilbarg and J. Milgram

Stanford University

Stanford, California 94305
University of Washington

Seattle, Washington 98105

ASSOCIATE EDITORS
E. F. BECKENBACH
B. H. NeumanN
F. WoLF
K. YosHIDA

\section{SUPPORTING INSTITUTIONS}

\author{
UNIVERSITY OF BRITISH COLUMBIA \\ CALIFORNIA INSTITUTE OF TECHNOLOGY \\ UNIVERSITY OF CALIFORNIA \\ MONTANA STATE UNIVERSITY \\ UNIVERSITY OF NEVADA \\ NEW MEXICO STATE UNIVERSITY \\ OREGON STATE UNIVERSITY \\ UNIVERSITY OF OREGON \\ OSAKA UNIVERSITY
}

\author{
UNIVERSITY OF SOUTHERN CALIFORNIA \\ STANFORD UNIVERSITY \\ UNIVERSITY OF TOKYO \\ UNIVERSITY OF UTAH \\ WASHINGTON STATE UNIVERSITY \\ UNIVERSITY OF WASHINGTON
* * * *
AMERICAN MATHEMATICAL SOCIETY \\ NAVAL WEAPONS CENTER
}

The Supporting Institutions listed above contribute to the cost of publication of this Journal, but they are not owners or publishers and have no responsibility for its content or policies.

Mathematical papers intended for publication in the Pacific Journal of Mathematics should be in typed form or offset-reproduced, (not dittoed), double spaced with large margins. Underline Greek letters in red, German in green, and script in blue. The first paragraph or two must be capable of being used separately as a synopsis of the entire paper. Items of the bibliography should not be cited there unless absolutely necessary, in which case they must be identified by author and Journal, rather than by item number. Manuscripts, in duplicate if possible, may be sent to any one of the four editors. Please classify according to the scheme of Math. Rev. Index to Vol. 39. All other communications to the editors should be addressed to the managing editor, or Elaine Barth, University of California, Los Angeles, California, 90024.

100 reprints are provided free for each article, only if page charges have been substantially paid. Additional copies may be obtained at cost in multiples of 50 .

The Pacific of Journal Mathematics is issued monthly as of January 1966. Regular subscription rate: $\$ 72.00$ a year (6 Vols., 12 issues). Special rate: $\$ 36.00$ a year to individual members of supporting institutions.

Subscriptions, orders for back numbers, and changes of address should be sent to Pacific Journal of Mathematics, 103 Highland Boulevard, Berkeley, California, 94708.

PUBLISHED BY PACIFIC JOURNAL OF MATHEMATICS, A NON-PROFIT CORPORATION

Printed at Kokusai Bunken Insatsusha (International Academic Printing Co., Ltd.), 270, 3-chome Totsuka-cho, Shinjuku-ku, Tokyo 160, Japan.

* C. R. DePrima California Institute of Technology, Pasadena, CA 91109, will replace J. Dugundji until August 1974.

Copyright (C) 1973 by Pacific Journal of Mathematics

Manufactured and first issued in Japan 


\section{Pacific Journal of Mathematics}

\section{Vol. 51, No. $2 \quad$ December, 1974}

Robert F. V. Anderson, Laplace transform methods in multivariate spectral theory .................................................. 339

William George Bade, Two properties of the Sorgenfrey plane . . . . . . . . . . . . 349

John Robert Baxter and Rafael Van Severen Chacon, Functionals on continuous

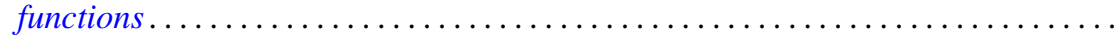

Phillip Wayne Bean, Helly and Radon-type theorems in interval convexity

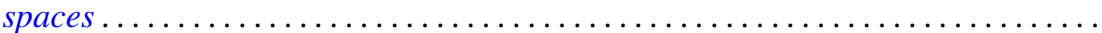

James Robert Boone, On k-quotient mappings $\ldots \ldots \ldots \ldots \ldots \ldots \ldots \ldots \ldots$

Ronald P. Brown, Extended prime spots and quadratic forms . . . . . . . . . . . .

William Hugh Cornish, Crawley's completion of a conditionally upper continuous lattice .............................................

Robert S. Cunningham, On finite left localizations ...................

Robert Jay Daverman, Approximating polyhedra in codimension one spheres

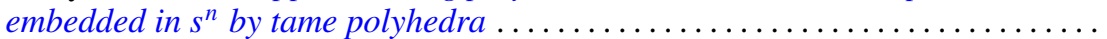

Burton I. Fein, Minimal splitting fields for group representations . . . . . . . . . . . .

Peter Fletcher and Robert Allen McCoy, Conditions under which a connected

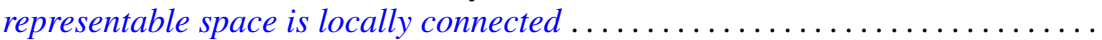

Jonathan Samuel Golan, Topologies on the torsion-theoretic spectrum of a noncommutative ring...

Manfred Gordon and Edward Martin Wilkinson, Determinants of Petrie matrices.

Alfred Peter Hallstrom, A counterexample to a conjecture on an integral condition for determining peak points (counterexample concerning peak points)........

E. R. Heal and Michael Windham, Finitely generated $F$-algebras with applications to Stein manifolds.

Denton Elwood Hewgill, On the eigenvalues of a second order elliptic operator in an unbounded domain ............................

Charles Royal Johnson, The Hadamard product of $A$ and $A^{*}$.

Darrell Conley Kent and Gary Douglas Richardson, Regular completions of Cauchy spaces.

Alan Greenwell Law and Ann L. McKerracher, Sharpened polynomial approximation

Bruce Stephen Lund, Subalgebras of finite codimension in the algebra of analytic functions on a Riemann surface. .

Robert Wilmer Miller, TTF classes and quasi-generators . .

Roberta Mura and Akbar H. Rhemtulla, Solvable groups in which every maximal partial order is isolated ....

Isaac Namioka, Separate continuity and joint continuity...

Alan Saleski, Entropy of self-homeomorphisms of statistical pseudo-metric

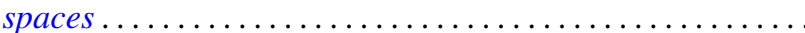

H. A. Seid, Cyclic multiplication operators on $L_{p}$-spaces .....

H. B. Skerry, On matrix maps of entire sequences ............

John Brendan Sullivan, A proof of the finite generation of invariants of a normal

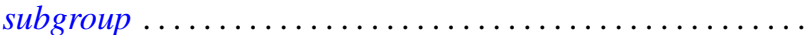

John Griggs Thompson, Nonsolvable finite groups all of whose local subgroups are

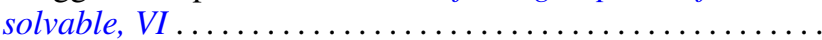

